\title{
A field method for avalanche danger-level verification
}

\author{
A. Gagnati, ${ }^{1}$ M. Valt, ${ }^{1}$ G. Soratroi,,${ }^{1}$ J. Gavaldà, ${ }^{2}$ C. G. Sellés ${ }^{2}$ \\ ${ }^{1}$ Centro Sperimentale Valanghe e Difesa Idrogeologica, I-32020 Arabba BL, Italy \\ ${ }^{2}$ Servei Geologic de Catalunya, Parc de Montjuic, 08038 Barcelona, Spain
}

\begin{abstract}
Even though the danger-level verification indicated in a bulletin should be a priority aim of avalanche-forecast services, there are no easily applicable verification methods available today. The main difficulty lies in the fact that avalanche observation is no longer sufficient. Therefore, it is necessary to verify the actual condition of the snowpack stability, particularly concerning low danger levels. This work introduces a procedure for "a posteriori" field verification of danger level, both in space and time (2472 hours). The method is based on the following elements: avalanche-activity survey, observation of cross-country skiers' activity, snow profiles and "Rutschblock" tests. These elements, relating both to time and the examination zone, are combined to provide an objective danger degree according to the European avalanche-danger scale. The method was used experimentally in the winter of 1993-94 in the Dolomites and subsequently, in the winter of 1995-96 in the Catalan Pyrenees. As far as 24 hour forecasts are concerned, the method has shown a forecast reliability of $93 \%$ in the Dolomites and $76 \%$ in the Catalan Pyrenees, while 48 hour forecasts have given values of $89 \%$ and $64 \%$, respectively. The lower degree of forecast reliability in the Catalan Pyrenees is accounted for by the unusual weather conditions of winter 1995-96, which was very snowy and characterized by few foreseeable avalanche conditions. The practical application of the proposed verification method has given encouraging results, thus allowing experts to find the main errors in order to improve future forecasts. However, simpler survey procedures are necessary in order to operate on a regional scale. The method is suitable for further development relating to verification of both degree of danger and danger localization.
\end{abstract}

\section{INTRODUCTION}

Verifying an avalanche-danger forecast means defining the forecast reliability through a comparison between the real and the foreseen avalanche danger. The main aim of avalanche-forecast verification is to determine the main errors in the regional or local avalanche bulletins in order to improve future forecasts. In the past, several authors (Judson and King, 1985; Giraud and others, 1987) have proposed verification methods based upon avalanche-activity indices; however, these are not sufficient for verification, for in such situations avalanche activity can be very reduced or even absent though there may be considerable avalanche danger (Föhn and Schweizer, 1995). That is why the real conditions of the snowpack stability must be checked. The European avalanche-bulletin services define the danger level from 1993 on by means of a scale which foresees five danger levels: low, moderate, considerable, high, very high (Cagnati, 1994) (see Table 1). The method proposed here aims at verifying the danger level using several field measures and personal observations, without considering localization of the danger.

\section{DESGRIPTION OF THE METHOD}

The first step consists of defining the real avalanche danger, concerning the day of verification. It deals with answering the following question: what is the danger level which describes the avalanche activity in the best way? It is considered possible to describe the situation correctly for $90 \%$ of the days (Schweizer and Föhn, 1996). In this paper, the dan- ger level is defined by means of the following elements: avalanche-activity observation, cross-country skiers' activity, stability tests and snowpack profiles. Thus, real avalanche danger is compared to foreseen avalanche danger in the regional or local bulletins. The forecast, which normally covers 24-72 hours, is done using the conventional method (LaChapelle, 1980) or the different models now available (statistic models, deterministic models, expert systems, etc.).

\section{Choice of the area}

The dimensions of the area on which verification is made must be small enough to allow detailed survey but also sufficiently large to present a complete variety of avalanche terrain and situations. One condition is that the chosen area is frequented by skiers. A skiing district with an area about $50-100 \mathrm{~km}^{2}$ is quite convenient. Besides, it is necessary to prepare an observation net with reliable observers. Apart from surveys in fixed places (observation sites, regional snowfields, automatic stations etc.) it is helpful to use observers who are experienced in travelling and are skilled climbers, for example, Alpine guides. The presence of control systems for avalanches (avalanche control by explosive, avalanche detection and warning systems) can also be useful.

\section{Natural avalanche activity}

The observation of natural avalanche activity forms the basis of the verification process even though it is insufficient in itself. For all the observed avalanches, it is necessary to define: release time, its nature and dimension, crown thick- 


\begin{tabular}{|c|c|c|c|}
\hline & Danger level & Snowpack stability & Avalanche probability \\
\hline 1 & Low & The snowpack is generally well bonded and stable & $\begin{array}{l}\text { Triggering is generally possible only with high additional loads, }{ }^{\dagger} \text { and a few steep } \\
\text { extreme slopes. Only a few small natural avalanches (sluffs) possible }\end{array}$ \\
\hline 2 & Moderate & $\begin{array}{l}\text { The snowpack is moderatelywell bonded on some } \\
\text { steep slopes," otherwise generally well bonded }\end{array}$ & $\begin{array}{l}\text { Triggering possible particularly with high additional loads }{ }^{+} \text {on the steep slopes } \\
\text { indicated in the bulletin. Large natural avalanches not likely }\end{array}$ \\
\hline 3 & Considerable & $\begin{array}{l}\text { The snowpack is moderately but weakly bonded on } \\
\text { many steep slopes* }\end{array}$ & $\begin{array}{l}\text { Triggering possible with low additional loads, }{ }^{\dagger} \text { particularly on the steep slopes } \\
\text { indicated in the bulletin. In certain conditions, medium and occasionally } \\
\text { large-sized natural avalanches may occur }\end{array}$ \\
\hline 4 & High & $\begin{array}{l}\text { The snowpack is weakly bonded on most steep } \\
\text { slopes* }\end{array}$ & $\begin{array}{l}\text { Triggering probable even with low additional loads }{ }^{\dagger} \text { on many steep slopes. In } \\
\text { some conditions, frequent medium- or large-sized natural avalanches are } \\
\text { likely }\end{array}$ \\
\hline 5 & Very high & $\begin{array}{l}\text { The snowpack is generally weakly bonded and } \\
\text { largely unstable }\end{array}$ & Numerous large natural avalanches are likely, even in moderately steep terrain \\
\hline
\end{tabular}

Explanations

* Generally described in more detail in the avalanche bulletin (e.g. altitude, aspect and type of terrain)

† Additional load: high: e.g. group of skiers, piste machine and avalanche blasting; low: e.g. skier and walker. Steep slopes: slopes with an incline of more than about $30^{\circ}$.

Steep extreme slopes: particularly unfavourable in terms of the incline, terrain profile, proximity to ridge, smoothness of underlying ground surface. Aspect: compass bearing directly down slope.

Natural: without human assistance.

Table 2. Natural avalanche typologies observed (Italian code) according to the European avalanche-danger scale and relative danger levels

\begin{tabular}{lcc}
\hline \multicolumn{1}{c}{ Type of observed avalanches } & Code & Danger level \\
\hline $\begin{array}{l}\text { No avalanche or natural small-sized } \\
\text { avalanches (sluffs) }\end{array}$ & 0,1 & $1,2,3$ \\
Natural medium-sized avalanches & 2 & 2,3 \\
Many natural medium-sized avalanches & 3 & 3,4 \\
Single natural and large avalanches & 4 & 3,4 \\
Numerous natural and large avalanches & 5 & 5 \\
& & \\
\hline
\end{tabular}

ness, causes of the release and its localization in the territory. In the case of induced release, it is useful to know the type of additional load which has caused the release (how many skiers? how many kilograms of explosive have been used?). The survey which has been used for the definition of avalanche type can be that used in the meteo-nivometric code of the daily survey. The observation of avalanche activity allows us to make a first discrimination in the danger level in Table 2.

\section{Observation of skiing activity}

The observation of the skiing evidence is a qualitative sign of the stability conditions of the snowpack. It must, of

Table 3. Observation of cross-country skiing activity and relative danger level

\begin{tabular}{cc}
\hline Cross-country skiing activity & Danger level \\
\hline Absent, previous or only flat terrain & Undetermined \\
Without triggering avalanches or release only with & 1,2 \\
$\quad$ high additional loads (skiing on extreme slopes) & \\
Triggering avalanches with low additional loads & $3,4,5$
\end{tabular}

course, refer to the natural snow cover, away from ski tracks and in zones which have not been previously passed by skiers. It is useful to know on what type of slope cross-country skiing has been practised (on all slopes, only on not such steep slopes, also on extreme slopes), at what altitude and aspects, and in the case of triggering, what the necessary additional load causing the release has been (single skier or a group of skiers). The relative danger-level correlation is listed in Table 3.

\section{Stability tests}

Stability tests indicate the stability conditions of the snow cover in a quantitative way. Slide blocks are formed on slope patterns (Föhn, 1987) but also other tests can be used such as the compression test or the shovel test. Concerning the test localization, it is convenient to conduct them in a discretional way rather than in fixed places, having an idea of what might be the most critical conditions. It is usually good to do at least two tests not far from one another, in order to come nearer to the median score representative of the slope (Jamieson and Johnston, 1993). The danger level is assigned according to Table 4 .

\section{Snowpack profiles}

The snowpack profiles can be performed in the same place as the stability tests but also in different places. Afterwards,

Table 4. Rutschblock levels and relative danger levels (according to Föhn, 1987)

\begin{tabular}{cc}
\hline Rutschblock score & Danger level \\
\hline Unsuccessful test & Undetermined \\
$1,2,3$ & 4,5 \\
4,5 & 3 \\
6 & 2 \\
7 & 1
\end{tabular}


Table 5. Typologies of snowpack profiles and relative danger levels
Snowpack profile

Danger level

Well bonded

Moderately bonded

Moderately to weakly bonded

Weakly bonded the profiles must be classified on the basis of typical typologies of the zone under control. One possible system of profile classification is that based on the hardness index but it is often useful to consider also the weak layer present within the snow cover (depth hoar, surface hoar, etc.).

In this paper, a four typologies classification has been considered (well bonded, moderately bonded, moderately to weakly bonded and weakly bonded) (see Table 5); it has been carried out on the basis of hardness-index trend relative to 15 years of observations in the Dolomites (see Fig. 1).

\section{Danger-level assignation}

The danger-level assignment for the day is made by observing the avalanche activity and considering the results of the other three observations.

CASE A: Numerous large and natural avalanches (code 5). Possible danger level: 5 .

No other confirmation of the danger level is necessary.

\begin{tabular}{|l|l|}
\hline Snowpack & Hardness index \\
\hline well bonded & \\
\hline $\begin{array}{l}\text { moderately } \\
\text { well bonded } \\
\text { moderately } \\
\text { bonded }\end{array}$ & \\
\hline $\begin{array}{l}\text { weakly } \\
\text { bonded }\end{array}$
\end{tabular}

Fig. 1. Classification of hardness index profile (Dolomites).
CASE B: Single large and natural avalanches (code 4). Possible danger level: 4,3 .

Level 4 is assigned if at least another element of verification assesses it: weakly bonded profiles, skiing activity with releases also with low additional load, rutschblock scores from 1 to 3 . Otherwise, level 3 is assigned.

CASE C: Many medium-sized natural avalanches (code 3). Possible danger levels: 3 and 4 .

Level 4 is assigned if at least another element confirms it (see case B). Otherwise, level 3 is assigned.

CASE D: Medium-sized natural avalanches (code 2). Possible danger levels: 2 and 3 .

Level 3 is assigned if at least two of the following other conditions are present: moderately to weakly bonded profiles, skiing activity with triggering also with low additional load, rutschblock scores from 4 to 5 . Otherwise, level 2 is assigned.

CASE E: Small-sized, natural avalanches or no natural avalanches (code 1 or 0). Possible danger levels: 1, 2 or 3 .

Level 3 is assigned, if at least another two specific conditions are checked (see case D). Level 1 is assigned if at least two of the following conditions are observed: wellbonded profiles, skiing activity also on extreme slopes, or rutschblock score 7. In other cases, level 2 is assigned.

\section{APPLICATIONS}

This verification method of the avalanche danger level has been tested in the Dolomites during the winter season of 1993-94 and successively in the Catalan Pyrenees in the winter of 1995-96. During the analysis of the results, the evaluation errors, caused by an incorrect weather forecast, have not been considered in both cases. Only those attributable to a wrong evaluation of the stability conditions of the snowpack have been considered.

\section{Application in the Dolomiti Alps}

In order to test the verification method, the zone of Arabba has been chosen. Arabba is a well-known tourist centre in the southern Dolomites. Besides being a much-frequented ski resort, it also presents a considerable variety of possible avalanche situations. Moreover, in Arabba there is the regional centre of avalanche forecasts for the Dolomites and Venetian Prealps. The verification has been performed on the weather and avalanche bulletin which is sent out daily by this centre. The bulletin normally contains an avalanche-danger forecast for the successive 24, 48 and 72 hours. Altogether, 40 bulletins have been checked; $32 \%$ of the total number of bulletins issued during the winter season. Situations with intermediate danger levels clearly prevailed in the cases examined, whereas situations with a very high danger level were completely absent. Altogether, the danger-level distribution has been the following: 7.5\% low, $65 \%$ moderate, $22.5 \%$ considerable, $5 \%$ high. The 24 hour forecast turned out to be correct in $93.1 \%$ of the examined cases, the 48 hour forecast in $88.9 \%$ and the 72 hour forecast in $71.4 \%$ (see Fig. 2). Errors in the dangerlevel evaluation never exceeded level 1 . In error cases, there was a tendency to overvalue the danger, above all in the 72 hour forecast; in only one case, relative to the 48 hour forecast, was the danger level undervalued. 

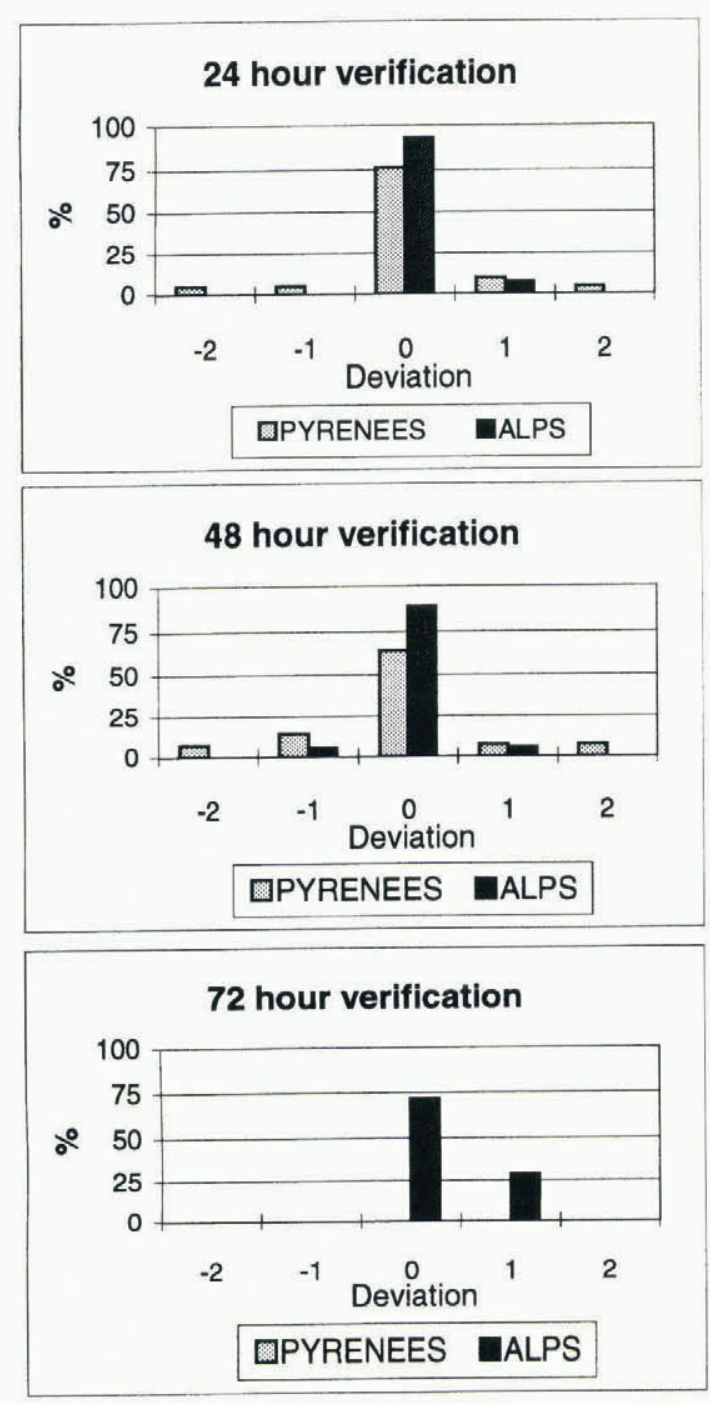

Fig. 2. Verification of the 24,48 and 72 hour forecast and error deviation.

\section{Application in the Gatalan Pyrenees}

In order to apply the field verification method in the Catalan Pyrenees, two spots have been chosen. One of them was in the Ulldeter sector (eastern Pyrenees) and the other in the Bonaigua sector (western Pyrenees). The two are different geographically and climatically so a wide diversity in the conditions of stability of the snow pack could be assured. Both test sites have the necessary characteristics to apply the method: wide panoramic views with a diversity of height and aspect, proximity to a ski resort, high usage by crosscountry skiers, snow and weather data records and easy access. When analysing the results of the verification method, errors in the contrast between forecast and effective-danger levels due to an incorrect weather forecast were not taken into account. These cases are not due to an incorrect analysis of the stability conditions of the snowpack, so this kind of error is outside the validation of the field method. A total of 32 avalanche-danger bulletins has been verified during the winter of 1995-96 in the Catalan Pyrenees; some $30 \%$ of the issued bulletins. The effective danger levels show the following distribution: $28.1 \%$ moderate, $50.0 \%$ considerable, $18.4 \%$ high and $3.1 \%$ very high. There was no case with a low danger level. The winter of 1995-96 registered the highest number of days with an elevated forecast danger level of the past ten winters. As far as 24 hour forecasts are concerned, the method has shown a forecast reliability of $76.2 \%$, while 48 hour forecasts have given a value of $64.3 \%$. Regarding 24 hour errors, a slight trend to overestimate the effective danger level has been detected. On the other hand, 48 hour errors have been generated especially by an undervaluation of the effective danger level.

\section{CONCLUSIONS}

The proposed method is only a first step towards defining operating procedures for the verification of avalanche danger which consider the real conditions of the snow pack stability. The applications in the Dolomites and Catalan Pyrenees have both examined sparse samples and therefore cannot constitute a sufficiently severe test, even if they have given a preliminary indication of the reliability level of the forecast in the respective areas and pointed out the main causes of error in formulating an avalanche forecast. Although both applications deal with regional bulletins, the method principally suits verification of the local bulletins (mesoscale), where it is easier to organize observational and data-collection systems which are sufficiently representative. Possible applications and future developments of this method should consider the necessity of verifying not only the danger level but also the areal distribution of danger, looking first at the altitude and the aspect of the dangerous slopes.

\section{REFERENCES}

Cagnati, A. 1994. Guida all'utilizzazione del bollettino nivometeorologico emesso dal Centro Sperimentale Valanghe di Arabba. Regione del Veneto, Dipartimento Foreste. Centro Sperimentale Valanghe e Difesa Idrogeologica.

Föhn, P. M. B. 1987. The "Rutschblock" as a practical tool for slope stability evaluation. International Association of Hydrological Sciences Publication 162 (Symposium at Davos 1986 - Avalanche Formation, Movement and Effects), 223-228.

Föhn, P. M. B. and J. Schweizer. 1995. Verification of avalanche danger with respect to avalanche forecasting. In Sivardière, F., ed. Les apports de la recherche scientifique à la sécurité neige, glace et avalanche. Actes de Colloque, Chamonix 30 mai-3 juin 1995. Grenoble, Association Nationale pour l'Étude de la Neige et des Avalanches (ANENA), 15l-156.

Giraud, G., J. Lafeuille and E. Pahaut. 1987. Évaluation de la qualité de la prévision du risque d'avalanche. International Association of Hydrological Sciences Publication 162 (Symposium at Davos 1986 - Avalanche Formation, Movement and Effects), 583-591.

Jamieson, J. B. and C. D. Johnston. 1993. Rutschblock precision, technique variations and limitations. 7. Glaciol., 39(133), 666-674.

Judson, A. and R. M. King. 1985. An index of regional snow-pack stability based on natural slab avalanches. 7. Glaciol., 31(108), 67-73.

LaChapelle, E. R. 1980. The fundamental processes in conventional avalanche forecasting. 7. Glaciol., 26(94), $75-84$.

Schweizer, J. and P. M. B. Föhn. 1996. Avalanche forecasting - an expert system approach. 7. Glaciol., 42(141), 318-332. 